\title{
Intelligent Playgrounds: Measuring and Affecting Social Inclusion in Schools
}

\author{
Olga Lyra ${ }^{1}$, Evangelos Karapanos ${ }^{2}$, and Vassilis Kostakos ${ }^{2}$ \\ ${ }^{1}$ Centro de Competência de Artes e Humanidades \\ ${ }^{2}$ Madeira Interactive Technologies Institute, \\ Universidade da Madeira \\ lyra.olga@gmail.com, \{ekarapanos,vk\}@uma.pt
}

\begin{abstract}
Equal access to education has recently been declared by the United Nations a basic human right [14]. However, despite the substantial attention given to inclusive education in recent years, researchers have criticized a lack of empirical evidence on how exclusion is manifested in student behavior. Recent development in sensor technology and social network analysis techniques can provide a new perspective to the impact of educational practices through the measurement of students' social interactions. In this paper we outline our research agenda that aims at a) measuring the current stand as well as the impact of inclusive educational interventions using sensor technology and sociometric analysis, and b) challenging pupils' perceptions of diversity with the aim of eliminating discriminatory behaviors in primary schools using persuasive games.
\end{abstract}

Keywords: Inclusive education, social networks, persuasive games.

\section{Introduction}

Inclusive Education represents an approach to education that seeks 'Education for All' through developing schools that respond successfully to the diversity of all learners and their different needs [15]. Equal access to education has recently been declared by the United Nations a basic human right. As of September 2009, most EU countries have signed the Ratification of the UN Convention whereby access to an inclusive educational system has become a legal right [14].

Schools have access to a number of operationalized techniques and methods for promoting inclusive school development, such as the Index for Inclusion [1], a tool being used in more than 40 countries. Index for Inclusion is designed to help schools in a) assessing their current stand with regard to inclusiveness, b) identifying the key topics of concern for the whole school community, and c) implementing concrete actions after reaching consensus among all members of the school community.

However, despite the substantial attention given to this educational approach in recent years, researchers have criticized a lack of empirical evidence on how exclusion is manifested in student behavior as well as the long-term effect of existing methodologies that promote inclusive school development [11]. Even when studies have attempted to capture how exclusion is manifested in students' social interactions 
within the class and during play time, their focus was limited to a number of school cases as well as particular dimensions of diversity, thus leading to an uncertainty of how such results may generalize to the larger population and how educational exclusion is manifested at large [6].

Recent development in sensor technology [4] and social network analysis techniques [10] can provide a new perspective to the impact of educational practices through the measurement of students' social interactions. For instance, proximity measurement during playtime capturing pupils' social interactions may be correlated with metrics of different dimensions of diversity such as ethnic origin, religion and native language, parents' socio-economic and educational background, forms of special needs and educational performance,. These in turn may affect a student's ability to participate in equal terms to the educational community. Capturing these metrics can possibly generate the ability to measure inclusiveness at large, through sampling a wide number of schools and over extended periods of time.

Secondly, grounded on data about pupils' social interactions and using persuasive techniques (Fogg, 2002), technology may be used in challenging pupils' perceptions of diversity with the aim of eliminating discriminatory behaviors in primary schools. In the remainder of the paper we outline our research agenda.

\section{Measuring the Inclusiveness of School Communities Using Sensor Technology and Sociometric Analysis}

Sociometric analysis has been used for describing communication patterns in organizations [4], inquiring into urban mobility [8], modeling knowledge propagation and other domains [2], leading to a new field of computational social science [9] motivated by our increasing ability to capture social phenomena at large. To our knowledge, however, such techniques have not yet been used to capture the development of pupils in schools. Using sensor technology to capture and quantify schools' inclusiveness provides the ability to generalize our findings as measurements can take place at a wide number of schools and through an extended period of time.

This objective will result in a palette of metrics that capture the inclusiveness of a school community based on pupils' social interactions. The metrics will take into account pupils' proximity data during school activities, physical activity (through accelerometer) and verbal activity (through microphone capture). In addition, dimensions of diversity such as ethnic origin, parents' socio-economic and educational background, forms special needs and others will be captured. These metrics will subsequently be used to assess the impact of the educational and technological interventions in the next two goals.

\section{Assessing the Impact of Inclusive School Development Interventions}

The impact of educational interventions, and specifically "Index for Inclusion" projects, will be assessed in terms of changes in pupils' social interactions, using sensor network technology. Index for inclusion projects will be executed in a number 
of schools and measurements of pupil's social interactions will be taken throughout the intervention. Pair-wise proximity will be the key measured variable but other variables such as physical activity (through accelerometer) and verbal activity (through microphone) will be captured. A combination of these measures will be used to express social activity, and will then be correlated with: a) Metrics of different dimensions of diversity that might affect a student's ability to participate in equal terms to the educational community such as ethnic origin, religion and native language, parents' socio-economic and educational background, forms special needs and educational performance, and b) stakeholders' perceptions of the inclusiveness of a school, and data elicited in the course of Index for Inclusion projects.

The analysis will look to develop models of how students interact with others, and will attempt to assess whether the social structure amongst students impacts their performance in school. This analysis will control for the various environmental variables that change from school to school.

\section{Persuasive Games That Challenge Children's Perceptions of Diversity and Demotivate Discriminatory Behaviors}

Construal theory [13] suggests that (perceived) social similarity, being it in the form of attitudes, physical characteristics etc., influences not only the available information, but also the cognitive process involved when individuals evaluate other's actions, with more distant individuals to be judged on more abstract attributes. It has been found that when individuals evaluate their own, and those of similar others, behavior, they emphasize the role of concrete situation factors that operate at the moment of action ("I stepped on your toe because the bus was crowded"), whereas when judging the behavior of more distant individuals, they emphasize the role of stable, general dispositional properties of the actor ("he stepped on my toe because he is clumsy") [13].

"Daily habits" is a persuasive game that attempts to increase of interpersonal similarity through capturing and communicating habits that are shared across different children that appear limited interaction in school. Habits will be sensed through the mobile phones and may include aspects of a child's daily life such as: wake-up time, sleeping time, or the amount, temporal and spatial range of physical activity.

However, motivating social behaviors brings significant complications, for instance, through group polarization [7], a phenomenon where people adopt more extreme response to deliberate acts when being in groups than when being alone.

Through minimalistic interventions we will attempt to measure the impact of two motivational techniques: reciprocity and operant conditioning. Reciprocity has been found to have positive effect in encouraging prosocial behaviors in primary schools [3]. It may be operationalized through the identification of positive changes in a pupil's social behavior (e.g. his or her centrality in the social network) and the communication of those to other pupils in the class. Operant conditioning [12] uses two primary tools: reinforcement and punishment. These may be operationalized in the form of a game where positive daily changes in a child's network centrality adds points to the child's profile while negative changes remove points. 


\section{Conclusion}

This paper presents a double-pronged research agenda aiming first to measure the status quo and impact of inclusive educational interventions using sensor technology and sociometric analysis. In addition, it aims to challenge pupils' perceptions of diversity with the aim of eliminating discriminatory behaviors in primary schools using persuasive games.

\section{References}

1. Booth, T., Ainscow, M.: Index for Inclusion. In: Developing Learning and Participation in Schools, 2nd edn. Centre for Studies on Inclusive Education, Bristol (2002)

2. Christensen, C., Albert, I., Grenfell, B., Albert, R.: Disease dynamics in a dynamic social network. Physica A: Statistical Mechanics and its Applications 389(13), 2663-2674 (2010) ISSN 0378-4371

3. Covington, M.V.: Goal theory, motivation, and school achievement: an integrative review. Annual Review of Psychology 51, 171-200 (2000)

4. Eagle, N., Pentland, A.: Reality Mining: Sensing Complex Social Systems. J. Personal and Ubiquitous Computing (2005)

5. Fogg, B.J.: Persuasive Technology: Using Computers to Change what We Think and do. In: Grudin, J., Nielsen, J., Card, S. (eds.) 1st edn., Science \& Technology Books (2002)

6. Fryxell, D., Kennedy, C.: Placement along the continuum of services and its impact on students' social relationships. Journal of the Association for Persons with Severe Handicaps 20, 259-269 (1995)

7. Isenberg, D.J.: Group polarization: A critical review and meta-analysis. Journal of Personality and Social Psychology 50(6), 1141-1151 (1986)

8. Kostakos, V., O'Neill, E., Penn, A., Roussos, G., Papadongonas, D.: Brief encounters: sensing, modelling and visualizing urban mobility and copresence networks. ACM Transactions on Computer Human Interaction 17(1), 1-38 (2010)

9. Lazer, D., Pentland, A., Adamic, L., Aral, S., Barabasi, A.-L., Brewer, D., Christakis, N., Contractor, N., Fowler, J., Gutmann, M., Jebara, T., King, G., Macy, M., Roy, D., Van Alstyne, M.: Computational Social Science. Science 323, 721-723 (2009)

10. Macindoe, O., Richards, W.: Graph Comparison using Fine Structure Analysis. In: Proc. IEEE SocCom 2010, Minneapolis, USA (2010)

11. Simpson, R.L.: Inclusion of Students with Behavior Disorders in General Education Settings: Research and Measurement Issues. Behavioral Disorders 30(1), 19-31 (2004)

12. Skinner, B.F.: The Technology of Teaching. Appleton-Century-Crofts, New York (1968)

13. Trope, Y., Liberman, N.: Construal-Level Theory of Psychological Distance. Psychological Review 117(2), 440-463 (2010); 463a, ISSN 0033-295X

14. UN: Convention on the Rights of Persons with Disabilities (2006)

15. UNESCO (1994): The Salamanca Statement and Framework for Action on Special Needs Education. Salamanca, Spain, June 7-10 (1994) 